\title{
Gerencia participativa y la promoción social en escuelas urbanas, Municipio Trujillo, Estado Trujillo, Venezuela
}

\author{
Participative management and the social promotion \\ in urban schools, Trujillo Municipality, Trujillo State, \\ Venezuela
}

\author{
Prof. Gilberto Antonio Bastidas Pacheco \\ Docente e Investigador del Departamento Salud Pública \\ Universidad de Carabobo \\ Carabobo, Venezuela. \\ bastidasprotozoo@hotmail.com \\ José Gregorio Pacheco Barrios \\ Docente Unidad Educativa Monseñor Dr. Etanislao Carrillo. \\ Trujillo, Venezuela.
}

Recibido: 13-VII-2011 • Aceptado 3-XI-2011 • Corregido 24-XII-2011

\begin{abstract}
Resumen: La promoción social está vinculada al logro de una nueva visión de escuela proyectada hacia su entorno, en tanto la gerencia participativa se relaciona con la gestión institucional, entendida como la búsqueda de la productividad administrativa y académica, a partir de un nuevo concepto de la acción gerencial que rompe con la dirección vertical y realza la toma de decisiones compartidas; estas premisas están contenidas en el proyecto educativo venezolano. El objetivo de esta investigación fue determinar dimensiones de las variables gerencia participativa $y$ promoción social en docentes y directores de escuelas urbanas del municipio de Trujillo, estado Trujillo, Venezuela. Se hizo una investigación descriptiva, de campo y correlacional basada en la encuesta y se usó el cuestionario como instrumento de recolección de información. Se encuestaron 11 directores y 38 docentes. Como resultados se dan los siguientes: los directores consideran buena y los docentes mala la gestión y la promoción social, con correlación positiva y fuerte entre ambas variables. Se concluye que para los docentes pero no para los directores la gestión es cerrada en las instituciones educativas estudiadas, distante del concepto de gerencia participativa; además, que se deja de lado el importante rol de promotor
\end{abstract}

\section{Introducción}

La gerencia participativa y la promoción social son aspectos importantes en una institución escolar por la naturaleza de las funciones cumplidas en beneficio de la sociedad. El rol del docente como promotor social está vinculado al logro de una nueva visión de escuela, proyectada esta hacia su entorno (Covey, 1994; Romero, 1996; Robbins, 1998; Márquez, 2006).

Por su parte, la gerencia participativa se relaciona con la gestión institucional, entendida como la búsqueda de la productividad administrativa y académica, a partir de un nuevo concepto de la acción gerencial que rompe con la dirección vertical y realza la toma de decisiones compartidas entre los actores de la escuela, es decir, los directores, docentes, personal 
social que deben exhibir todos los actores involucrados en la educación formal.

Palabras claves: Gerencia participativa, promoción social, docente, director

\begin{abstract}
The social promotion is linked to the attainment of a new sight of school, projected, towards your environment, meanwhile the participative management it is related with the institutional step, understand as the search of the administrative and academic productivity, as of a new concept of the management action, which breaks with the vertical address and embosses the shared decision making, anticipated these contained in the educational Venezuelan project. The objective of this investigation was determining dimensions of the variable participative management and social promotion in teachers and directors of urban schools of the Trujillo municipality, Trujillo state, Venezuela. Descriptive investigation, of field and correlational, based on the inquiry and with the questionnaire as instrument of collection of information. Went 11 the directors and 38 the teachers. Result: the directors consider good and the educational mail the step and the social promotion, with positive and strong correlation between both variables. It concludes. That for the educational, but not for the directors, the step is closed in the educational affected, distant facilities of the concept of participative management and to him stops to side, the important role of social promoter that they must exhibit all involucrate actors in the formal education.
\end{abstract}

Keywords: Participative management, social promotion, teacher, director administrativo, obreros, alumnos, padres y/o representantes y miembros de la comunidad en general. Este modelo permite el desarrollo de una adecuada y oportuna instrumentación de estrategias que evita las asincronías en la ejecución de actividades (Covey, 1994; Romero, 1996; Robbins, 1998; Márquez, 2006).

En este sentido, la práctica de la gerencia participativa a nivel institucional pareciera estar estrechamente ligada con la promoción social, un papel que implica $\mathrm{su}$ compromiso hacia el logro de metas $\mathrm{u}$ objetivos propuestos en beneficio primeramente de la escuela y, en segundo lugar, pero igual de importante, de la comunidad (Briceño, 2001).

Dicho en otros términos, la práctica de la gerencia participativa en una institución escolar podría ser una de las variables determinantes en la promoción social, al entender que el director es la persona llamada a propiciar o negar las condiciones necesarias para un trabajo sinérgico en la escuela, así como a cultivar la motivación de los demás actores del ámbito educativo hacia el desempeño eficaz y comprometido de sus responsabilidades (Briceño, 2001).

Máxime que no existe aún consenso definitivo para la definición del ser humano como gerente, pues para algunos, se relaciona con la facultad de dirigir estratégicamente a las personas (Kotter, 1998). Para otros, la gerencia implica "don de mando y habilidad para orientar las acciones de los demás, en función de alcanzar objetivos de interés compartido" (Smith, 1999).

Igualmente, se considera al gerente como la persona que ve en sus colaboradores inmediatos y en los demás trabajadores elementos de apoyo a su gestión gerencial (Robins, 1998). Este modelo gerencial fue transferido al ámbito educativo, quizás como respuesta a las premisas de integración y pertinencia propuestas previamente en la Constitución de la República Bolivariana de Venezuela (1999) y luego en el Proyecto Educativo Nacional (2000). Este modelo requiere de un docente primero 
autor y luego actor de transformaciones, capaz de reflexionar y accionar con visión de futuro, que siente el cambio en sí mismo y en el entorno, preparado para actuar estratégicamente con objetivos definidos, evaluables y reajustables siempre en procura del bien social.

Todo esto en total armonía con la acción comunitaria por medio del acceso continúo de las organizaciones comunitarias en la toma de decisiones y en el diseño de planes de trabajo en respuesta a las necesidades sociales, con especial interés en el proceso de enseñanza-aprendizaje. En este orden de ideas, inspirar en el docente la promoción social es crucial para el éxito o fracaso del o los proyectos educativos comunitarios, como factor integrante del perfil, según se entiende aquí, del buen docente, debido a su papel protagónico en la construcción del país de todos y para todos, al ser el motivador del entorno que lo rodea.

La integración de la escuela y la comunidad en la resolución de problemas educativos es de tal importancia que en la actualidad se realizan experiencias con el objeto de incentivar el interés y preocupación de los docentes en los problemas comunitarios, orientadas algunas de estas experiencias hacia el ofrecimiento y por supuesto la adquisición de conocimientos, habilidades y destrezas que aseguren la posición de liderazgo que parece corresponderle al docente (Poleo, 1995).

\section{El objeto de estudio:}

En Venezuela el impacto gerencial de las nuevas tendencias no ha sido interiorizado en su totalidad por muchas instituciones educativas. Esto posiblemente porque muchos directores asumen el cargo sin un compromiso claro para formular, no se sienten identificados ni con los propósitos institucionales, ni con las necesidades y requerimientos de sus dirigidos; igualmente no practican la relación cara a cara, ni están preparados para el abordaje de los adelantos tecnológicos en materia comunicacional, lo que sumerge en un letargo de indiferencia y de pasividad a los miembros de la comunidad escolar (Requeijo y Lugo, 1995; Odremán, 1997; Cárdenas, 1998).

Estos obstáculos del sistema educativo venezolano y por ende trujillano se mencionan también en el proyecto educativo nacional (2000) así como la toma de decisiones vertical y emanada del nivel central, rigidez administrativa, planificación normativa, escasa supervisión y pobre comunicación (Siles, 2004; Marcano, 2007; González, 2008).

La consideración del concepto de gerencia participativa, aunque relativamente nuevo en el contexto educativo, adquiere relevancia porque trasciende la simple asignación de tareas y se nutre de la oportunidad de compartir responsabilidades, sin presiones e imposiciones que puedan en última instancia limitar la autonomía o toma de decisiones, las cuales serán en todo caso compartidas (Siles, 2004; Marcano, 2007; González, 2008).

En ese sentido, el gerente participativo cede poder pero mantiene un sólido liderazgo personal e institucional para recibir apoyo. Ello genera acciones sincronizadas, las cuales acarrean resultados positivos, ya que los actores de las escuelas bajo estas circunstancias gerenciales valoran adecuadamente las fortalezas y debilidades internas hacia dentro de las escuelas y hacia fuera de las mismas, así como las oportunidades y amenazas del entorno social en las cuales están inmersas estas instituciones de enseñanza (Siles, 2004; Marcano, 2007; González, 2008).

Actualmente, en el siglo XXI, y en virtud de la transformación del sistema educativo por medio de una reforma del nivel de educación primaria, la práctica de la gerencia participativa se perfila como uno de los aspectos esenciales para el logro de resultados productivos en las diversas instituciones escolares de Venezuela y, por consiguiente, del estado Trujillo. Esto 
ya que en función de la misma se pueden armonizar los diversos elementos del proceso educativo en atención a las políticas establecidas por el Estado venezolano, los objetivos institucionales, así como las necesidades y expectativas planteadas en la comunidad local (Siles, 2004; González, 2008).

En otros términos, la gerencia participativa podría coadyuvar al logro de resultados educativos concurrentes con las necesidades o expectativas planteadas en el entorno de la escuela (Siles, 2004; González, 2008). De allí la importancia del desempeño del director, entendido por los fundamentos de la gerencia participativa como uno de los principales factores de los cuales depende la calidad de la educación (Marcano, 2007).

Además, el papel de promotor social del docente, el adecuado, requiere que este sea investigador, es decir, conocedor de la realidad social en la que está inmersa la escuela y por lo tanto, la comunidad que la alberga. De igual manera, debe ser planificador de estrategias de intervención para dar respuesta a las necesidades internas de la escuela y a su entorno (Azuaje, 2007; Carrillo, 2007).

Del mismo modo, incumbe al docente el ser motivador, con alto grado de credibilidad y confianza, e inspirador de respeto y actitudes proactivas hacia el trabajo eficiente, solidario y cooperativo. Asimismo, corresponde al docente en su papel de promotor social ser orientador del proceso de aprendizaje escolar para actuar en función de objetivos comunes, con base en la definición de criterios por consenso y en la optimización de los recursos (Azuaje, 2007; Carrillo, 2007).

Es de esperar que las prácticas de gerencia participativa y promoción social del docente se perfilen como aspectos esenciales para el logro de resultados concretos en las diversas instituciones escolares de Venezuela, porque en función de las mismas se pueden armonizar los diversos elementos del proceso educativo, en atención a las políticas establecidas por el Estado y los objetivos institucionales, así como las necesidades y expectativas planteadas en la comunidad local. En pocas palabras, la gerencia participativa y la promoción social podrían coadyuvar al logro de resultados educativos concurrentes con las necesidades o expectativas planteadas en el entorno escolar.

Aunque se hacen llamados en pro del máximo desempeño en el ámbito educativo y social con base en la relación armónica entre la gestión del director y la acción de los docentes, en función de lograr un sinergismo entre sus actuaciones fundamentado en la comunicación bidireccional, la toma de decisiones por consenso y en la definición de proyectos de trabajo vinculados a la problemática local e institucional, estos llamados no son del todo atendidos. Se deja de lado la práctica de la gerencia participativa y el desempeño del docente se circunscribe solo a las actividades del aula de clases, sin una vinculación directa con el entorno institucional (Márquez, 2006).

Como es del dominio público, en Venezuela esta situación no ha permitido que el sector educativo mejore de acuerdo a las expectativas planteadas a pesar de las continuas reformas hechas. Esto debido, entre otros factores, a la debilidad en los sistemas gerenciales establecidos, lo que compromete seriamente el desarrollo de la educación venezolana.

Toda vez que la gestión del director no es participativa, se deja de ser el director, como afirma Pachano (2006, p.12): "El pivote capaz de incentivar a los demás miembros de la escuela, padres y docentes, así como otros actores de la comunidad hacia un desempeño más eficiente y efectivo".

El escenario es igualmente difícil en Trujillo, según estudio realizado por Medina (2006), quien señala que solo 13,4\% de los docentes entrevistados por su equipo han recibido entrenamiento en promoción social; además, en 19,8\% de las instituciones evaluadas no existen planes de trabajo definidos; asimismo, 42,3\% de los directores ejercen una gestión ajena a la realidad institucional y $71,3 \%$ de los mismos tienen 
una comunicación vertical con los demás actores del ámbito escolar.

En forma explícita los directores se limitan exclusivamente a cumplir funciones administrativas, centradas en el manejo de recaudos para el desarrollo de las actividades escolares y a impartir instrucciones emanadas de lineamientos establecidos desde instancias superiores, muchos de ellos descontextualizados, sin ofrecer salidas para el desarrollo autónomo y mucho menos para la discusión de estrategias que permitan alcanzar objetivos.

Por otro lado, la actuación del docente se circunscribe al aula de clase, sin trascender al proceso de enseñanza-aprendizaje del estudiante. Con esta acción impide que su aporte, en todo caso solidario, llegue a las comunidades. A esto se suma que el trabajo del docente es encasillado dentro de un programa curricular rígido, en función de cumplir determinados contenidos, sin dársele oportunidad de innovar.

El objetivo de la presente investigación se centró en determinar dimensiones de las variables gerencia participativa del director y la del docente como promotor social en escuelas urbanas del municipio Trujillo, estado Trujillo, Venezuela. Aspectos hasta ahora no investigados en la zona. Esto particularmente en las escuelas básicas de primera y segunda etapa, donde el currículo básico nacional (Ministerio de Educación y Deportes, 1997) exige un aprendizaje constructivista, con base en las experiencias significativas de los niños y niñas y con la participación de todos los actores involucrados en el proceso educativo, a través de los proyectos educativos integrales comunitarios (PEIC) y los proyectos pedagógicos de aula (PPA) (Ministerio de Educación y Deportes, 2005).

\section{Materiales y métodos:}

En el abordaje documental del tema se revisaron teorías en dos vertientes: por un lado, las referidas a la gerencia participativa, básicamente las basadas en las dimensiones gestión, liderazgo, comunicación y trabajo en equipo; por otro lado, las centradas en la promoción social, específicamente en las dimensiones investigador, planificador, orientador y motivador, categorías que permiten definir ambas variables.

Metodológicamente el trabajo fue descriptivo, y el diseño de campo y la investigación correlacional, pues se verificó estadísticamente el grado de relación entre las dos variables. Previo a la correlación se operacionalizaron las variables del estudio con el fin de desagregar aspectos inherentes o constitutivos de la gerencia participativa y del rol de promotor social de los docentes y directores (Tabla 1).

El tamaño de la población estudiada se obtuvo mediante censos escuela por escuela y se cotejó con información aportada por la Zona Educativa, órgano oficial del estado. La población total entre directores y docentes en escuelas urbanas del municipio Trujillo, estado Trujillo, Venezuela fue de 11 para los primeros (por tener las mismas atribuciones a este grupo se adicionó a los subdirectores) y de 38 para los segundos (ver Tabla 2). En virtud de que la población es relativamente pequeña, de fácil manejo y determinación se consideró como muestra a la población total.

La técnica empleada en la recolección de información fue la encuesta, específicamente el cuestionario. Luego de una previa explicación de los objetivos de la investigación se obtuvo el consentimiento informado de cada uno de los sujetos que participaron en este estudio y se garantizó la confidencialidad de la información aportada.

Con respecto a la medición del comportamiento de las variables gerencia participativa y promoción social, se recurrió a la aplicación de dos instrumentos a directores, subdirectores y docentes, con preguntas de respuestas cerradas (Tabla 3).

Se recurrió a un cuestionario para medir cada variable. Los cuestionarios fueron estructurados de la siguiente forma 
una fase introductoria (datos de identificación del mismo), justificación (propósito de su aplicación), objetivos (finalidad de la investigación), instrucciones generales (orientación con respecto a la forma de responder), criterios de evaluación (definición de puntajes para cada alternativa) e ítems de la prueba, 60 en total, 30 preguntas para medir el comportamiento de cada variable según sus indicadores y en concordancia con la operacionalización.

En cada cuestionario con el objetivo de medir la confiabilidad se estableció un puntaje entre uno (1) y cinco (5) para cada

Tabla 1

Operacionalización de las variables de la investigación

\begin{tabular}{|c|c|c|c|c|}
\hline Objetivo específico & Variable & Dimensión & Indicador & $\mathrm{N}^{\circ}$ Ítem \\
\hline \multirow{4}{*}{$\begin{array}{l}\text { Identificar } \\
\text { elementos de } \\
\text { la gerencia } \\
\text { participativa } \\
\text { en instituciones } \\
\text { educativas urbanas, } \\
\text { del municipio } \\
\text { Trujillo, estado } \\
\text { Trujillo. }\end{array}$} & \multirow{4}{*}{$\begin{array}{l}\text { La gerencia } \\
\text { participativa }\end{array}$} & Gestión & $\begin{array}{l}\text { Capacitación } \\
\text { Motivación } \\
\text { permanente } \\
\text { Coordinación de } \\
\text { esfuerzos }\end{array}$ & $\begin{array}{l}1,2,3 \\
4,5,6 \\
7,8,9\end{array}$ \\
\hline & & Liderazgo & $\begin{array}{l}\text { Capacidad e } \\
\text { imaginación } \\
\text { creadora } \\
\text { Retos personales } \\
\text { Apertura al cambio }\end{array}$ & $\begin{array}{l}10,11,12 \\
13,14 \\
15,16,17\end{array}$ \\
\hline & & Comunicación & $\begin{array}{l}\text { Reuniones } \\
\text { constantes } \\
\text { Comunicación } \\
\text { bidireccional } \\
\text { Escucha activa }\end{array}$ & $\begin{array}{l}18,19,20 \\
21,22 \\
23,24\end{array}$ \\
\hline & & Trabajo en equipo & $\begin{array}{l}\text { Organización de } \\
\text { equipos } \\
\text { Asignación de } \\
\text { responsabilidades } \\
\text { Definición de tareas }\end{array}$ & $\begin{array}{l}25,26 \\
27,28 \\
29,30\end{array}$ \\
\hline \multirow{3}{*}{$\begin{array}{l}\text { Describir la } \\
\text { promoción social } \\
\text { en instituciones } \\
\text { educativas urbanas, } \\
\text { del municipio } \\
\text { Trujillo, estado } \\
\text { Trujillo. }\end{array}$} & \multirow{3}{*}{ La promoción social } & Investigador & $\begin{array}{l}\text { Problemática } \\
\text { institucional } \\
\text { Problemática } \\
\text { comunitaria } \\
\text { Capital social } \\
\text { disponible }\end{array}$ & $\begin{array}{l}1,2,3,4 \\
5,6,7 \\
8,9,10,11\end{array}$ \\
\hline & & Planificador & $\begin{array}{l}\text { Diagnóstico de rea- } \\
\text { lidad existente } \\
\text { Planes de acción } \\
\text { Estrategias de } \\
\text { intervención }\end{array}$ & $\begin{array}{l}12,13,14 \\
15,16,17,18 \\
19,20,21\end{array}$ \\
\hline & & Orientador & $\begin{array}{l}\text { Participación } \\
\text { comunitaria } \\
\text { Proyectos } \\
\text { productivos } \\
\text { Lineamientos } \\
\text { estratégicos }\end{array}$ & $\begin{array}{l}22,23,24 \\
25,26,27 \\
28,29,30\end{array}$ \\
\hline
\end{tabular}

Fuente: diseñado por los autores. 
una de las cinco (5) alternativas de respuesta. El sujeto de estudio marcó con una (X) su elección de respuesta. Los criterios para la determinación de los puntajes fueron establecidos de acuerdo con la escala siguiente: nunca (1), casi nunca (2), algunas veces (3), casi siempre (4) y siempre (5). Con el propósito de realizar asociación y análisis, por una parte, las alternativas "casi nunca" y "nunca" se consideraron negativas o contrarias al rasgo que se mide; por otra parte, "casi siempre" y "siempre" como positivas o a favor del rasgo.

Los instrumentos fueron previamente validados mediante juicio de expertos y en la determinación de la confiabilidad se aplicó una prueba piloto a una submuestra de directores y docentes, diferentes de aquellos objetos de este estudio, pero que ejercen sus funciones en escuelas y comunidades con características similares. Para la evaluación de la prueba piloto se seleccionó el método "confiabilidad por mitades”. El valor que alcanzó el cuestionario sobre gerencia participativa del director fue $\mathrm{rtt}=0.64$ y con la corrección de Spearman Brown de $\mathrm{rtt}=0.77$. Ahora bien, el cuestionario sobre el rol del docente como promotor social alcanzó un valor de $\mathrm{rtt}=0.71$ y con la corrección de Spearman Brown el valor fue de $\mathrm{rtt}=0.83$.

Los datos obtenidos fueron introducidos en una base de datos creada con el programa Microsoft Excel® con el propósito de realizar el análisis estadístico. Para el análisis se aceptó un nivel de confianza de $95 \%$ y un error estándar de 5\%. Además de estadísticos descriptivos, frecuencias absolutas y relativas, se realizaron análisis de asociación para determinar el grado de relación entre variables de interés mediante el programa estadístico SPSS $₫$ versión 13. Los resultados se muestran en tablas y gráficos en barras.

Tabla 2

Directores y docentes de las escuelas estadales urbanas del municipio Trujillo, estado Trujillo-Venezuela

\begin{tabular}{|c|c|c|c|c|}
\hline $\begin{array}{c}\text { Institución } \\
\text { Unidad Educativa (UE) }\end{array}$ & Director & Subdirector & Docentes & Total \\
\hline UE. Dr. Andrés Lomelli Rosario & 1 & 2 & 17 & 20 \\
\hline UE. Monseñor Estanislao Carrillo & 1 & 3 & 9 & 13 \\
\hline UE. Monseñor Rafal María Villasmil & 1 & 1 & 6 & 8 \\
\hline UE. Rosario Carrillo Heredia & 1 & 1 & 6 & 8 \\
\hline Total & 4 & 7 & 38 & 49 \\
\hline
\end{tabular}

Fuente: Visitas a las escuelas y Zona Educativa, estado Trujillo- Venezuela. 
Tabla 3

Preguntas de respuestas cerradas empleadas en la investigación

\begin{tabular}{l} 
Gerencia participativa \\
\hline 1 Actualiza al personal respecto a la aplicación de \\
diversas metodologías de trabajo al nivel institucional. \\
2 Capacita al personal de esta institución acerca del \\
desarrollo de proyectos educativos. \\
3 Orienta al personal en lo referente a la aplicación de \\
estrategias de gestión frente a los problemas \\
confrontados.
\end{tabular}

4 Reconoce al personal los logros alcanzados durante su trabajo.

5 Ayuda al personal a satisfacer las necesidades profesionales.

6 Toma en cuenta el esfuerzo realizado por los miembros en la institución.

7 Estimula la coordinación del trabajo institucional para evitar el despilfarro de recursos.

8 Busca el consenso grupal para la planificación de acciones al nivel institucional.

9 Propicia la unificación de criterios de trabajo para el logro de los objetivos propuestos.

10 Propone alternativas de gestión innovadoras en los problemas confrontados en la institución

11 Aplica soluciones viables ante las situaciones imprevistas.

12 Obtiene resultados originales como producto de las acciones ejecutadas.

13 Asume responsabilidades de trabajo sin importar la complejidad del mismo.

14 Se exige como gerente un alto perfil de rendimiento laboral.

15 Toma en cuenta las innovaciones ofrecidas por el entorno institucional.

16 Practica la autocrítica como una manera de fortalecer su liderazgo institucional.

17 Orienta la gestión institucional a las nuevas realidades educativas.

18 Intercambia puntos de vista acerca de la gestión institucional con las demás personas del plantel.

19 Mantiene contacto permanente con el personal de la institución.

20 Apoya su gestión tomando en cuenta las opiniones de otras personas para lograr la productividad institucional.

\section{Promoción social}

1 Muestra interés por la problemática administrativa de la institución.

2 Indaga acerca de la carencia de recursos materiales dentro de la institución.

3 Se interesa por conocer la tecnología de trabajo académico aplicada en la institución.

4 Muestra interés por conocer los factores incidentes en la relación escuela -comunidad.

5 Investiga acerca de los problemas comunitarios.

6 Busca herramientas de solución a la problemática comunitaria.

7 Investiga la problemática comunitaria que incide en el proceso de aprendizaje escolar.

8 Busca información acerca del capital social Recuperado de la comunidad.

9 Determina los aportes que puede realizar los representantes en beneficio de la institución.

10 Se interesa por conocer los vínculos establecidos entre la escuela e instituciones de la comunidad.

11 Muestra interés por conocer los aportes de la comunidad para el cumplimiento de programas socioeducativos desarrollados en la institución.

12 Investiga aspectos que definen la realidad institucional.

13 Se apoya en el diagnóstico como herramienta de calidad para estudiar la realidad comunitaria.

14 Se interesa por el conocimiento del entorno de actuación.

15 Elabora planes de acción para abordar las tareas requeridas en la institución.

16 Diseña planes de acción para priorizar las actividades a desarrollar en la institución.

17 Señala en los planes de acción cada una de las tareas a cumplir.

18 Adecua los planes de acción elaborados a las necesidades de la institución.

19 Para la atención de un problema, toma en cuenta todos los factores incidentes en el mismo.

20 Sistematiza previamente las actividades a desarrollar en procura de atender la problemática escolar. 


\begin{tabular}{|c|c|}
\hline Gerencia participativa & Promoción social \\
\hline $\begin{array}{l}21 \text { Se apoya en la implementación de instrucciones } \\
\text { directas a los miembros del plantel. }\end{array}$ & $\begin{array}{l}21 \text { Tiene claros los procedimientos a ser aplicados al } \\
\text { momento de atender un problema escolar. }\end{array}$ \\
\hline $\begin{array}{l}22 \text { Coordina la comunicación a un mismo nivel para } \\
\text { facilitar la comprensión del mensaje. }\end{array}$ & $\begin{array}{l}22 \text { Se apoya en la participación comunitaria para } \\
\text { hacer efectiva su labor como docente. }\end{array}$ \\
\hline $\begin{array}{l}23 \text { Muestra interés por los planteamientos de las } \\
\text { demás personas. }\end{array}$ & $\begin{array}{l}23 \text { Incentiva a los representantes a participar como } \\
\text { colaboradores de las actividades a realizar. }\end{array}$ \\
\hline $\begin{array}{l}24 \mathrm{Al} \text { conversar con otra persona, se ubica en su } \\
\text { mundo emocional sin hacer valoración subjetiva de } \\
\text { ella. }\end{array}$ & $\begin{array}{l}24 \text { Promueve la participación comunitaria para } \\
\text { fortalecer el proceso de aprendizaje del estudiante. }\end{array}$ \\
\hline $\begin{array}{l}25 \text { Organiza el trabajo institucional tomando en } \\
\text { cuenta la complementariedad de las potencialidades } \\
\text { en las personas. }\end{array}$ & $\begin{array}{l}25 \text { Orienta proyectos productivos en la escuela } \\
\text { tomando en cuenta las potencialidades de la } \\
\text { comunidad. }\end{array}$ \\
\hline $\begin{array}{l}26 \text { Propicia la unión de esfuerzos para facilitar el } \\
\text { logro de objetivos institucionales. }\end{array}$ & $\begin{array}{l}26 \text { Asesora proyectos productivos que satisfagan las } \\
\text { necesidades de la institución. }\end{array}$ \\
\hline $\begin{array}{l}27 \text { Delega responsabilidades de trabajo en el personal } \\
\text { de la institución. }\end{array}$ & $\begin{array}{l}27 \text { Orienta la formación de valores de trabajo en los } \\
\text { estudiantes a partir de proyectos productivos. }\end{array}$ \\
\hline $\begin{array}{l}28 \text { Identifica las tareas que puede asumir cada } \\
\text { persona en la institución. }\end{array}$ & $\begin{array}{l}28 \text { Define objetivos a corto plazo en función del } \\
\text { proceso de aprendizaje de los estudiantes. }\end{array}$ \\
\hline $\begin{array}{l}29 \text { Organiza las tareas a desarrollar mediante un } \\
\text { plan de trabajo previo a su ejecución. }\end{array}$ & $\begin{array}{l}29 \text { Planifica lineamientos de acción que responden a } \\
\text { la identidad institucional. }\end{array}$ \\
\hline $\begin{array}{l}30 \text { Planifica las tareas a desarrollar en base a las } \\
\text { necesidades presentes en la institución. }\end{array}$ & $\begin{array}{l}30 \text { Focaliza el desarrollo de las acciones para evitar el } \\
\text { uso innecesario de recursos. }\end{array}$ \\
\hline
\end{tabular}

Fuente: diseñado por los autores.

\section{Resultados:}

Los directores en $78,8 \%$ de los casos en promedio casi siempre $(48,5 \%)$ o siempre $(30,3 \%)$ capacitan, motivan o coordinan los esfuerzos de sus subalternos. Sin embargo, solo $10,5 \%$ de los docentes piensan de la misma manera sobre estos indicadores: casi siempre $(4,4 \%)$ y siempre $(6,1 \%)$. Igualmente se aprecia diferencias significativas entre las respuestas positivas (casi siempre y siempre) y negativas (casi nunca y nunca) emitidas por los directores: $\mathrm{p}<0.001$ y los docentes: $\mathrm{p}<0.001$ (Tabla 4).

Los resultados obtenidos con la evaluación de la dimensión liderazgo muestran, según la opinión de los docentes, la carencia de alternativas innovadoras de gestión para la resolución de los problemas que confronta la institución educativa. $\mathrm{Al}$ respecto, 15/38 de los docentes encuestados en promedio en cuanto a los indicadores que buscan medir la mencionada dimensión revelan que perciben en los directores dificultad para la apertura al cambio, sin retos personales o con escasa imaginación; por lo tanto, no existe adecuada motivación hacia el logro de objetivos.

En contraposición y como aspecto interesante los directores, respecto a esta evaluación, se sienten adecuadamente capacitados, como lo muestra la proporción dada por ellos al conjunto de alternativas positivas: casi siempre $(36,4 \%)$ y siempre (48,5\%). Asimismo, se aprecia diferencia significativa entre las respuestas positivas y negativas expresadas por directores y docentes: $p<0.001$ para ambos actores educativos (Tabla 5).

Existen debilidades en cuanto a la comunicación que debe entablarse entre directores y docentes de escuelas urbanas del municipio Trujillo, indispensable para la consecución de las metas planteadas, ya que en promedio $23 / 38(42,1 \%)$ de los 
Tabla 4

Preguntas de respuestas cerradas empleadas en la investigación

\begin{tabular}{|c|c|c|c|c|c|c|c|c|c|c|c|c|}
\hline \multirow{4}{*}{ Indicador } & \multicolumn{12}{|c|}{ Director/subdirector* } \\
\hline & \multicolumn{12}{|c|}{ Alternativasv } \\
\hline & \multicolumn{2}{|c|}{ Siempre } & \multicolumn{2}{|c|}{ Casi siempre } & \multicolumn{2}{|c|}{ Algunas veces } & \multicolumn{2}{|c|}{ Casi nunca } & \multicolumn{2}{|c|}{ Nunca } & \multicolumn{2}{|c|}{ Total } \\
\hline & $\mathrm{F}$ & $\%$ & $\mathrm{f}$ & $\%$ & $\mathrm{f}$ & $\%$ & $\mathrm{f}$ & $\%$ & $\mathrm{f}$ & $\%$ & $\mathrm{f}$ & $\%$ \\
\hline Capacitación & 5 & 45,5 & 4 & 36,4 & 2 & 18,2 & 0 & 0,0 & 0 & 0,0 & 11 & 100 \\
\hline $\begin{array}{l}\text { Motivación } \\
\text { permanente }\end{array}$ & 5 & 45,5 & 4 & 36,4 & 1 & 9,1 & 1 & 9,1 & 0 & 0,0 & 11 & 100 \\
\hline $\begin{array}{l}\text { Coordinación } \\
\text { de esfuerzos }\end{array}$ & 6 & 54,5 & 2 & 18,2 & 3 & 27,3 & 0 & 0,0 & 0 & 0,0 & 11 & 100 \\
\hline Promedio & 5,3 & 48,5 & 3,3 & 30,3 & 2,0 & 18,2 & 0,3 & 3,0 & 0,0 & 0,0 & 11,0 & 100 \\
\hline Sujeto & \multicolumn{12}{|c|}{ Docente ${ }^{* *}$} \\
\hline \multirow[t]{2}{*}{ Indicador } & \multicolumn{2}{|c|}{ Siempre } & \multicolumn{2}{|c|}{ Casi siempre } & \multicolumn{2}{|c|}{ Algunas veces } & \multicolumn{2}{|c|}{ Casi nunca } & \multicolumn{2}{|c|}{ Nunca } & \multicolumn{2}{|c|}{ Total } \\
\hline & $\mathrm{F}$ & $\%$ & $\mathrm{f}$ & $\%$ & $\mathrm{f}$ & $\%$ & $\mathrm{f}$ & $\%$ & $\mathrm{f}$ & $\%$ & $\mathrm{f}$ & $\%$ \\
\hline Capacitación & 2 & 5,3 & 1 & 2,6 & 19 & 50,0 & 10 & 26,3 & 6 & 15,8 & 38 & 100,0 \\
\hline $\begin{array}{l}\text { Motivación } \\
\text { permanente }\end{array}$ & 2 & 5,3 & 2 & 5,3 & 18 & 47,4 & 9 & 23,7 & 7 & 18,4 & 38 & 100,0 \\
\hline $\begin{array}{l}\text { Coordinación } \\
\text { de esfuerzos }\end{array}$ & 3 & 7,9 & 2 & 5,3 & 17 & 44,7 & 11 & 28,9 & 5 & 13,2 & 38 & 100,0 \\
\hline Promedio & 2,3 & 6,1 & 1,7 & 4,4 & 18,0 & 47,4 & 10,0 & 26,3 & 6,0 & 15,8 & 38,0 & 100,0 \\
\hline
\end{tabular}

Fuente: cuestionarios aplicados a directores y docentes.

Pearson: *p<0.001 con diferencia significativa entre respuestas positivas (casi siempre y siempre) y negativas (casi nunca y nunca) en directores.

$* * p<0.001$ con diferencia significativa entre respuestas positivas (casi siempre y siempre) y negativas (casi nunca y nunca) en docentes.

Tabla 5

Determinación de la dimensión liderazgo de la variable gerencia participativa en directores y docentes de escuelas urbanas, municipio Trujillo, estado Trujillo-Venezuela

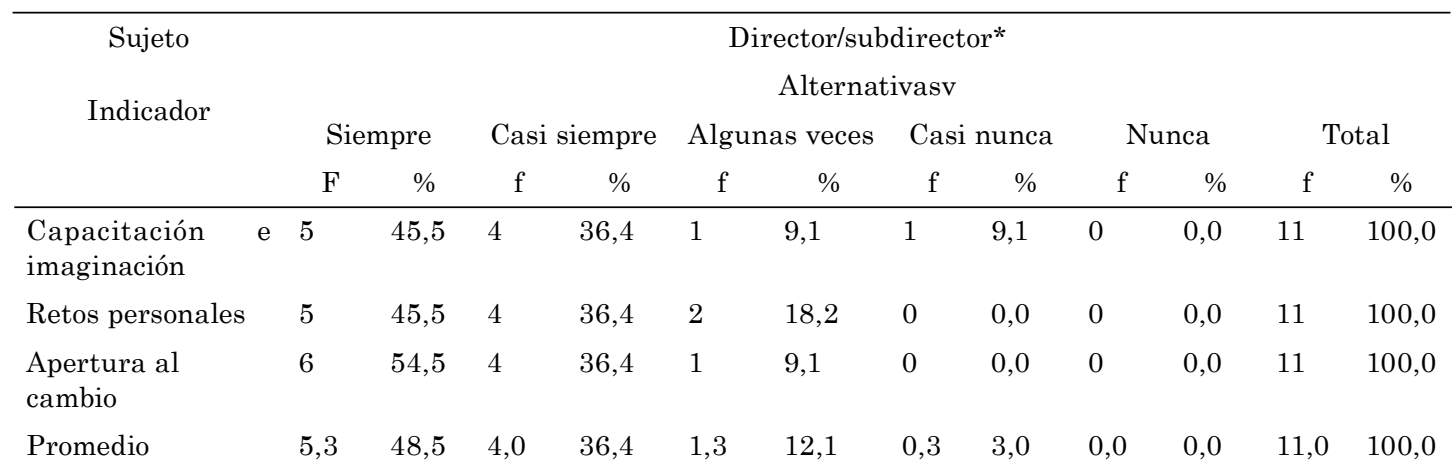




\begin{tabular}{|c|c|c|c|c|c|c|c|c|c|c|c|c|}
\hline \multirow{3}{*}{$\begin{array}{l}\text { Sujeto } \\
\text { Indicador }\end{array}$} & \multicolumn{12}{|c|}{ Docente** } \\
\hline & \multicolumn{2}{|c|}{ Siempre } & \multicolumn{2}{|c|}{ Casi siempre } & \multicolumn{2}{|c|}{ Algunas veces } & \multicolumn{2}{|c|}{ Casi nunca } & \multicolumn{2}{|c|}{ Nunca } & \multicolumn{2}{|c|}{ Total } \\
\hline & $\mathrm{F}$ & $\%$ & $\mathrm{f}$ & $\%$ & $\mathrm{f}$ & $\%$ & $\mathrm{f}$ & $\%$ & $\mathrm{f}$ & $\%$ & $\mathrm{f}$ & $\%$ \\
\hline $\begin{array}{l}\text { Capacitación } \\
\text { imaginación }\end{array}$ & e 1 & 2,6 & 3 & 7,9 & 19 & 50,0 & 8 & 21,1 & 7 & 18,4 & 38 & 100,0 \\
\hline Retos personales & 2 & 5,3 & 4 & 10,5 & 17 & 44,7 & 7 & 18,4 & 8 & 21,1 & 38 & 100,0 \\
\hline $\begin{array}{l}\text { Apertura al } \\
\text { cambio }\end{array}$ & 2 & 5,3 & 3 & 7,9 & 18 & 47,4 & 8 & 21,1 & 7 & 18,4 & 38 & 100,0 \\
\hline Promedio & 1,7 & 4,4 & 3,3 & 8,8 & 18,0 & 47,4 & 7,7 & 20,2 & 7,3 & 19,3 & 38,0 & 100,0 \\
\hline
\end{tabular}

Fuente: cuestionarios aplicados a directores y docentes.

Pearson: * $\mathrm{p}<0.001$ con diferencia significativa entre respuestas positivas (casi siempre y siempre) y negativas (casi nunca y nunca) en directores.

$* * \mathrm{p}<0.001$ con diferencia significativa entre respuestas positivas (casi siempre y siempre) y negativas (casi nunca y nunca) en docentes.

docentes encuestados creen que casi nunca $(30,7 \%)$ o nunca $(11,4 \%)$ se realizan reuniones, se actúa como escuchas activas o se mantiene comunicación bidireccional entre los miembros de la comunidad educativa.

Se oponen los directores a esta percepción al creer que hacen su papel gerencial; así lo afirman $87,8 \%$ de los mismos con diferencias significativas entre las respuestas positivas (casi siempre y siempre) y negativas (casi nunca y nunca) pronunciadas por directores: $\mathrm{p}<0.00001)$ y docentes: $\mathrm{p}<0.0001$ (Tabla 6).

Tabla 6

Determinación de la dimensión comunicación de la variable gerencia participativa en directores y docentes de escuelas urbanas, municipio Trujillo, estado Trujillo-Venezuela

\begin{tabular}{|c|c|c|c|c|c|c|c|c|c|c|c|c|}
\hline \multirow{4}{*}{$\begin{array}{c}\text { Sujeto } \\
\text { Indicador }\end{array}$} & \multicolumn{12}{|c|}{ Director/subdirector* } \\
\hline & \multirow{2}{*}{\multicolumn{2}{|c|}{ Siempre }} & \multicolumn{8}{|c|}{ Alternativasv } & \multirow{2}{*}{\multicolumn{2}{|c|}{ Total }} \\
\hline & & & \multicolumn{2}{|c|}{ Casi siempre } & \multicolumn{2}{|c|}{ Algunas veces } & \multicolumn{2}{|c|}{ Casi nunca } & \multicolumn{2}{|c|}{ Nunca } & & \\
\hline & $\mathrm{F}$ & $\%$ & $\mathrm{f}$ & $\%$ & $\mathrm{f}$ & $\%$ & $\mathrm{f}$ & $\%$ & $\mathrm{f}$ & $\%$ & $\mathrm{f}$ & $\%$ \\
\hline $\begin{array}{l}\mathrm{R} \text { e u n i o n e s } \\
\text { constantes }\end{array}$ & 7 & 63,6 & 3 & 27,3 & 1 & 9,1 & 0 & 0,0 & 0 & 0,0 & 11 & 100,0 \\
\hline $\begin{array}{l}\text { Comunicación } \\
\text { bidireccional }\end{array}$ & 7 & 63,6 & 3 & 27,3 & 1 & 9,1 & 0 & 0,0 & 0 & 0,0 & 11 & 100,0 \\
\hline Escucha activa & 7 & 63,6 & 2 & 18,2 & 2 & 18,2 & 0 & 0,0 & 0 & 0,0 & 11 & 100,0 \\
\hline Promedio & 7,0 & 63,6 & 3 & 24,2 & 1,3 & 12,1 & 0,0 & 0,0 & 0,0 & 0,0 & 11,0 & 100,0 \\
\hline Sujeto & \multicolumn{12}{|c|}{ Docente ${ }^{* *}$} \\
\hline Indicador & \multicolumn{2}{|c|}{ Siempre } & \multicolumn{2}{|c|}{ Casi siempre } & \multicolumn{2}{|c|}{ Algunas veces } & \multicolumn{2}{|c|}{ Casi nunca } & \multicolumn{2}{|c|}{ Nunca } & \multicolumn{2}{|c|}{ Total } \\
\hline & $\mathrm{F}$ & $\%$ & $\mathrm{f}$ & $\%$ & $\mathrm{f}$ & $\%$ & $\mathrm{f}$ & $\%$ & $\mathrm{f}$ & $\%$ & $\mathrm{f}$ & $\%$ \\
\hline $\begin{array}{l}\mathrm{R} \text { e u n i o n e s } \\
\text { constantes }\end{array}$ & 3 & 7,9 & 2 & 5,3 & 18 & 47,4 & 11 & 28,9 & 4 & 10,5 & 38 & 100,0 \\
\hline $\begin{array}{l}\text { Comunicación } \\
\text { bidireccional }\end{array}$ & 3 & 7,9 & 2 & 5,3 & 17 & 44,7 & 11 & 28,9 & 5 & 13,2 & 38 & 100,0 \\
\hline
\end{tabular}




\begin{tabular}{lllllllllllll} 
Escucha activa & 2 & 5,3 & 1 & 2,6 & 18 & 47,4 & 13 & 34,2 & 4 & 10,5 & 38 & 100,0 \\
Promedio & 2,7 & 7,0 & 1,7 & 4,4 & 17,7 & 46,5 & 11,7 & 30,7 & 4,3 & 11,4 & 38,0 & 100,0 \\
\hline
\end{tabular}

Fuente: cuestionarios aplicados a directores y docentes.

Pearson: ${ }^{*} \mathrm{p}<0.00001$ con diferencia significativa entre respuestas positivas (casi siempre y siempre) y negativas (casi nunca y nunca) en directores.

$* * p<0.0001$ con diferencia significativa entre respuestas positivas (casi siempre y siempre) y negativas (casi nunca y nunca) en docentes.

Los resultados muestran que en promedio 16/38 de los docentes encuestados manifestaron que en sus instituciones casi nunca $(27 \%)$ o nunca $(14 \%-\mathrm{p}<0.0001 \mathrm{con}$ respecto al promedio de las alternativas siempre + casi siempre-) se organiza el trabajo institucional de acuerdo con la asignación de responsabilidades, organización de equipos y definición de tareas según las potencialidades de las personas. Por otro lado, la mayoría de los directores, creen que impulsan el trabajo en equipo con la adecuada definición y asignación de tareas $(\mathrm{p}<0.001$; ver Tabla 7$)$.

Tabla 7

Determinación de la dimensión trabajo en equipo de la variable gerencia participativa en directores y docentes de escuelas urbanas, municipio Trujillo, estado Trujillo-Venezuela

\begin{tabular}{|c|c|c|c|c|c|c|c|c|c|c|c|c|}
\hline \multirow{4}{*}{ Indicador } & \multicolumn{12}{|c|}{ Director/subdirector* } \\
\hline & \multicolumn{12}{|c|}{ Alternativasv } \\
\hline & \multicolumn{2}{|c|}{ Siempre } & \multicolumn{2}{|c|}{ Casi siempre } & \multicolumn{2}{|c|}{ Algunas veces } & \multicolumn{2}{|c|}{ Casi nunca } & \multicolumn{2}{|c|}{ Nunca } & \multicolumn{2}{|c|}{ Total } \\
\hline & $\mathrm{F}$ & $\%$ & $f$ & $\%$ & $\mathrm{f}$ & $\%$ & $f$ & $\%$ & $\mathrm{f}$ & $\%$ & $f$ & $\%$ \\
\hline $\begin{array}{l}\text { Organización } \\
\text { de equipos }\end{array}$ & 5 & 45,5 & 4 & 36,4 & 1 & 9,1 & 1 & 9,1 & 0 & 0,0 & 11 & 100,0 \\
\hline $\begin{array}{l}\text { Asignación de } \\
\text { responsabili- } \\
\text { dad }\end{array}$ & 5 & 45,5 & 4 & 36,4 & 2 & 18,2 & 0 & 0,0 & 0 & 0,0 & 11 & 100,0 \\
\hline $\begin{array}{l}\text { Definición de } \\
\text { tareas }\end{array}$ & 5 & 45,5 & 4 & 36,4 & 1 & 9,1 & 1 & 9,1 & 0 & 0,0 & 11 & 100,0 \\
\hline Promedio & 5,0 & 45,5 & 4,0 & 36,4 & 1,3 & 12,1 & 0,7 & 6,1 & 0,0 & 0,0 & 11,0 & 100,0 \\
\hline Sujeto & \multicolumn{12}{|c|}{ Docente ${ }^{* *}$} \\
\hline \multirow[t]{2}{*}{ Indicador } & \multicolumn{2}{|c|}{ Siempre } & \multicolumn{2}{|c|}{ Casi siempre } & \multicolumn{2}{|c|}{ Algunas veces } & \multicolumn{2}{|c|}{ Casi nunca } & \multicolumn{2}{|c|}{ Nunca } & \multicolumn{2}{|c|}{ Total } \\
\hline & $\mathrm{F}$ & $\%$ & $\mathrm{f}$ & $\%$ & $\mathrm{f}$ & $\%$ & $f$ & $\%$ & $\mathrm{f}$ & $\%$ & $\mathrm{f}$ & $\%$ \\
\hline $\begin{array}{l}\text { Organización } \\
\text { de equipos }\end{array}$ & 3 & 7,9 & 2 & 5,3 & 17 & 44,7 & 11 & 28,9 & 5 & 13,2 & 38 & 100,0 \\
\hline $\begin{array}{l}\text { Asignación de } \\
\text { responsabili- } \\
\text { dad }\end{array}$ & 2 & 5,3 & 2 & 5,3 & 18 & 47,4 & 9 & 23,7 & 7 & 18,4 & 38 & 100,0 \\
\hline $\begin{array}{l}\text { Definición de } \\
\text { tareas }\end{array}$ & 2 & 5,3 & 1 & 2,6 & 19 & 50,0 & 10 & 26,3 & 6 & 15,8 & 38 & 100,0 \\
\hline Promedio & 2,3 & 6,1 & 1,7 & 4,4 & 18,0 & 47,4 & 10,0 & 26,3 & 6,0 & 15,8 & 38,0 & 100,0 \\
\hline
\end{tabular}

Fuente: cuestionarios aplicados a directores y docentes.

Pearson: ${ }^{*} \mathrm{p}<0.001$ con diferencia significativa entre respuestas positivas (casi siempre y siempre) y negativas (casi nunca y nunca) en directores.

$* * \mathrm{p}<0.0001$ con diferencia significativa entre respuestas positivas (casi siempre y siempre) y negativas (casi nunca y nunca) en docentes. 
Los problemas institucionales, comunitarios y de capital social disponible no son el centro del quehacer diario de los integrantes de la comunidad educativa de escuelas urbanas del municipio Trujillo, pues solo 4 docentes de los encuestados $(p<0.0001)$ opinan que esto es así; es decir, que sí existe intervención constante de la comunidad educativa, como capital social, en la solución de sus problemas y los de la comunidad. No obstante, la mayoría de los directores opinan lo contrario: $\mathrm{p}<0.00001$ (Tabla 8).

Tabla 8

Determinación de la dimensión docente investigador perteneciente a la variable promoción social en directores y docentes de escuelas urbanas, municipio Trujillo, estado Trujillo-Venezuela

\begin{tabular}{|c|c|c|c|c|c|c|c|c|c|c|c|c|}
\hline \multirow{4}{*}{ Indicador } & \multicolumn{12}{|c|}{ Director/subdirector* } \\
\hline & \multicolumn{12}{|c|}{ Alternativasv } \\
\hline & \multicolumn{2}{|c|}{ Siempre } & \multicolumn{2}{|c|}{ Casi siempre } & \multicolumn{2}{|c|}{ Algunas veces } & \multicolumn{2}{|c|}{ Casi nunca } & \multicolumn{2}{|c|}{ Nunca } & \multicolumn{2}{|c|}{ Total } \\
\hline & $\mathrm{F}$ & $\%$ & $\mathrm{f}$ & $\%$ & $\mathrm{f}$ & $\%$ & $\mathrm{f}$ & $\%$ & f & $\%$ & $\mathrm{f}$ & $\%$ \\
\hline $\begin{array}{l}\text { Problemática } \\
\text { institucional }\end{array}$ & 6 & 54,5 & 4 & 36,4 & 1 & 9,1 & 0 & 0,0 & 0 & 0,0 & 11 & 100,0 \\
\hline $\begin{array}{l}\text { Problemática } \\
\text { comunitaria }\end{array}$ & 6 & 54,5 & 4 & 36,4 & 1 & 9,1 & 0 & 0,0 & 0 & 0,0 & 11 & 100,0 \\
\hline $\begin{array}{l}\text { Capital social } \\
\text { disponible }\end{array}$ & 6 & 54,5 & 4 & 36,4 & 1 & 9,1 & 0 & 0,0 & 0 & 0,0 & 11 & 100,0 \\
\hline Promedio & 6 & 54,5 & 4 & 36,4 & 1 & 9,1 & 0 & 0,0 & 0 & 0,0 & 11 & 100,0 \\
\hline Sujeto & \multicolumn{12}{|c|}{ Docente $^{* *}$} \\
\hline \multirow[t]{2}{*}{ Indicador } & \multicolumn{2}{|c|}{ Siempre } & \multicolumn{2}{|c|}{ Casi siempre } & \multicolumn{2}{|c|}{ Algunas veces } & \multicolumn{2}{|c|}{ Casi nunca } & \multicolumn{2}{|c|}{ Nunca } & \multicolumn{2}{|c|}{ Total } \\
\hline & $\mathrm{F}$ & $\%$ & $\mathrm{f}$ & $\%$ & $\mathrm{f}$ & $\%$ & $\mathrm{f}$ & $\%$ & $\mathrm{f}$ & $\%$ & $\mathrm{f}$ & $\%$ \\
\hline $\begin{array}{l}\text { Problemática } \\
\text { institucional }\end{array}$ & 2 & 5,3 & 3 & 7,9 & 17 & 44,7 & 12 & 31,6 & 4 & 10,5 & 38 & 100,0 \\
\hline $\begin{array}{l}\text { Problemática } \\
\text { comunitaria }\end{array}$ & 2 & 5,3 & 3 & 7,9 & 18 & 47,4 & 10 & 26,3 & 5 & 13,2 & 38 & 100,0 \\
\hline $\begin{array}{l}\text { Capital social } \\
\text { disponible }\end{array}$ & 1 & 2,6 & 2 & 5,3 & 17 & 44,7 & 14 & 36,8 & 4 & 10,5 & 38 & 100,0 \\
\hline Promedio & 1,7 & 4,4 & 2,7 & 7,0 & 17,3 & 45,6 & 12,0 & 31,6 & 4,3 & 11,4 & 38,0 & 100,0 \\
\hline
\end{tabular}

Fuente: cuestionarios aplicados a directores y docentes.

Pearson: ${ }^{*} \mathrm{p}<0.00001$ con diferencia significativa entre respuestas positivas (casi siempre y siempre) y negativas (casi nunca y nunca) en directores.

$* * p<0.0001$ con diferencia significativa entre respuestas positivas (casi siempre y siempre) y negativas (casi nunca y nunca) en docentes.

Únicamente 5/38 en promedio de los docentes participantes en el estudio opinan que de forma habitual se presta atención a los planes de acción para abordar las tareas requeridas en la institución y se siguen estrategias de intervención para atender los problemas educativos, siempre con el apoyo del diagnóstico como herramienta indispensable para develar la realidad institucional $(p<0.001$ con diferencia significativa entre el promedio de los grupos de alternativas: siempre + casi siempre y casi nunca + nunca). 
La planificación en la promoción social según la mayoría de los directores es lo cotidiano en el día a día de las escuelas del municipio Trujillo $(p<0.001$ con diferencia significativa entre el promedio de los grupos de alternativas: siempre + casi siempre y casi nunca + nunca; ver Tabla 9).

Tabla 9

Determinación de la dimensión docente planificador perteneciente a la variable promoción social en director y docentes de escuelas urbanas, municipio Trujillo, estado Trujillo-Venezuela

\begin{tabular}{|c|c|c|c|c|c|c|c|c|c|c|c|c|}
\hline \multirow{4}{*}{$\begin{array}{c}\text { Sujeto } \\
\text { Indicador }\end{array}$} & \multicolumn{12}{|c|}{ Director/subdirector* } \\
\hline & \multicolumn{12}{|c|}{ Alternativasv } \\
\hline & \multicolumn{2}{|c|}{ Siempre } & \multicolumn{2}{|c|}{ Casi siempre } & \multicolumn{2}{|c|}{ Algunas veces } & \multicolumn{2}{|c|}{ Casi nunca } & \multicolumn{2}{|c|}{ Nunca } & \multicolumn{2}{|c|}{ Total } \\
\hline & $\mathrm{F}$ & $\%$ & $\mathrm{f}$ & $\%$ & $f$ & $\%$ & $\mathrm{f}$ & $\%$ & $\mathrm{f}$ & $\%$ & $\mathrm{f}$ & $\%$ \\
\hline $\begin{array}{l}\text { Diagnóstico } \\
\text { de la realidad }\end{array}$ & 6 & 15,1 & 3 & 12,1 & 1 & 10,1 & 1 & 10,1 & 0 & 9,1 & 11 & 100,0 \\
\hline $\begin{array}{l}\text { Planes de } \\
\text { acción }\end{array}$ & 6 & 15,1 & 3 & 12,1 & 1 & 10,1 & 1 & 10,1 & 0 & 9,1 & 11 & 100,0 \\
\hline $\begin{array}{l}\text { Estrategias de } \\
\text { intervención }\end{array}$ & 6 & 15,1 & 3 & 12,1 & 1 & 10,1 & 1 & 10,1 & 0 & 9,1 & 11 & 100,0 \\
\hline Promedio & 6 & 15,1 & 3 & 12,1 & 1 & 10,1 & 1 & 10,1 & 0 & 9,1 & 11 & 100,0 \\
\hline Sujeto & \multicolumn{12}{|c|}{ Docente $^{* *}$} \\
\hline \multirow[t]{2}{*}{ Indicador } & \multicolumn{2}{|c|}{ Siempre } & \multicolumn{2}{|c|}{ Casi siempre } & \multicolumn{2}{|c|}{ Algunas veces } & \multicolumn{2}{|c|}{ Casi nunca } & \multicolumn{2}{|c|}{ Nunca } & \multicolumn{2}{|c|}{ Total } \\
\hline & $\mathrm{F}$ & $\%$ & $\mathrm{f}$ & $\%$ & $f$ & $\%$ & $\mathrm{f}$ & $\%$ & $\mathrm{f}$ & $\%$ & $\mathrm{f}$ & $\%$ \\
\hline $\begin{array}{l}\text { Diagnóstico } \\
\text { de la realidad }\end{array}$ & 3 & 7,9 & 2 & 5,3 & 18 & 47,4 & 11 & 28,9 & 4 & 10,5 & 38 & 100,0 \\
\hline $\begin{array}{l}\text { Planes de } \\
\text { acción }\end{array}$ & 2 & 5,3 & 1 & 2,6 & 18 & 47,4 & 13 & 34,2 & 4 & 10,5 & 38 & 100,0 \\
\hline $\begin{array}{l}\text { Estrategias de } \\
\text { intervención }\end{array}$ & 3 & 7,9 & 2 & 7,9 & 17 & 44,7 & 11 & 28,9 & 5 & 13,2 & 38 & 100,0 \\
\hline Promedio & 3 & 7,9 & 2 & 5,3 & 18 & 47,4 & 11 & 28,9 & 4 & 10,5 & 38 & 100,0 \\
\hline
\end{tabular}

Fuente: cuestionarios aplicados a directores y docentes.

Pearson: *p<0.001 con diferencia significativa entre respuestas positivas (casi siempre y siempre) y negativas (casi nunca y nunca) en directores.

$* * \mathrm{p}<0.001$ con diferencia significativa entre respuestas positivas (casi siempre y siempre) y negativas (casi nunca y nunca) en docentes.

Las respuestas afirmativas en promedio de directores (10/11) y docentes (16/38) indican que no hay una visión común entre los primeros y los segundos con respecto a directrices que orienten la formación de los estudiantes en valores para el trabajo a partir de proyectos productivos; en este sentido y para los docentes es notoria la indiferencia en el asesoramiento de proyectos productivos en la escuela sobre las bases de las potencialidades de la comunidad, específicamente la participación comunitaria. Sin embargo, para los directores estas actividades son prácticas comunes en sus instituciones educativas $(\mathrm{p}<0.00001$ [directores] y $\mathrm{p}<0.000001$ [docentes] entre el promedio de los grupos de alternativas: siempre + casi siempre y casi nunca + nunca; ver Tabla 10). 
Tabla 10

Determinación de la dimensión docente orientador perteneciente a la variable promoción social en directores y docentes de escuelas urbanas, municipio Trujillo, estado Trujillo-Venezuela

\begin{tabular}{|c|c|c|c|c|c|c|c|c|c|c|c|c|}
\hline \multirow{4}{*}{ Indicador } & \multicolumn{12}{|c|}{ Director/subdirector* } \\
\hline & \multicolumn{12}{|c|}{ Alternativasv } \\
\hline & \multicolumn{2}{|c|}{ Siempre } & \multicolumn{2}{|c|}{ Casi siempre } & \multicolumn{2}{|c|}{ Algunas veces } & \multicolumn{2}{|c|}{ Casi nunca } & \multicolumn{2}{|c|}{ Nunca } & \multicolumn{2}{|c|}{ Total } \\
\hline & $\mathrm{F}$ & $\%$ & $\mathrm{f}$ & $\%$ & $\mathrm{f}$ & $\%$ & $f$ & $\%$ & $f$ & $\%$ & $\mathrm{f}$ & $\%$ \\
\hline $\begin{array}{l}\text { Participación } \\
\text { comunitaria }\end{array}$ & 6 & 54,5 & 4 & 36,4 & 1 & 9,1 & 0 & 0,0 & 0 & 0,0 & 11 & 100,0 \\
\hline $\begin{array}{l}\text { Proyectos } \\
\text { productivos }\end{array}$ & 6 & 54,5 & 4 & 36,4 & 1 & 9,1 & 0 & 0,0 & 0 & 0,0 & 11 & 100,0 \\
\hline $\begin{array}{l}\text { Lineamientos } \\
\text { estratégicos }\end{array}$ & 7 & 63,6 & 3 & 27,3 & 1 & 9,1 & 0 & 0,0 & 0 & 0,0 & 11 & 100,0 \\
\hline Promedio & 6,3 & 57,6 & 3,7 & 33,3 & 1,0 & 9,1 & 0,0 & 0,0 & 0,0 & 0,0 & 11,0 & 100,0 \\
\hline Sujeto & \multicolumn{12}{|c|}{ Docente ${ }^{* *}$} \\
\hline \multirow[t]{2}{*}{ Indicador } & \multicolumn{2}{|c|}{ Siempre } & \multicolumn{2}{|c|}{ Casi siempre } & \multicolumn{2}{|c|}{ Algunas veces } & \multicolumn{2}{|c|}{ Casi nunca } & \multicolumn{2}{|c|}{ Nunca } & \multicolumn{2}{|c|}{ Total } \\
\hline & $\mathrm{F}$ & $\%$ & $\mathrm{f}$ & $\%$ & $\mathrm{f}$ & $\%$ & $\mathrm{f}$ & $\%$ & $f$ & $\%$ & $\mathrm{f}$ & $\%$ \\
\hline $\begin{array}{l}\text { Participación } \\
\text { comunitaria }\end{array}$ & 3 & 7,9 & 2 & 5,3 & 17 & 44,7 & 11 & 28,9 & 5 & 13,2 & 38 & 100,0 \\
\hline $\begin{array}{l}\text { Proyectos } \\
\text { productivos }\end{array}$ & 2 & 5,3 & 1 & 2,6 & 18 & 47,4 & 13 & 34,2 & 4 & 10,5 & 38 & 100,0 \\
\hline $\begin{array}{l}\text { Lineamientos } \\
\text { estratégicos }\end{array}$ & 3 & 7,9 & 2 & 5,3 & 18 & 47,4 & 11 & 28,9 & 4 & 10,5 & 38 & 100,0 \\
\hline Promedio & 2,7 & 7,0 & 1,7 & 4,4 & 17,7 & 46,5 & 11,7 & 30,7 & 4,3 & 11,4 & 38,0 & 100,0 \\
\hline
\end{tabular}

Fuente: cuestionarios aplicados a directores y docentes.

Pearson: ${ }^{*} \mathrm{p}<0.00001$ con diferencia significativa entre respuestas positivas (casi siempre y siempre) y negativas (casi nunca y nunca) en directores.

${ }^{* *} p<0.000001$ con diferencia significativa entre respuestas positivas (casi siempre y siempre) y negativas (casi nunca y nunca) en docentes.

Se resalta que no hubo diferencia significativa por género o edad con respecto a las respuestas emitidas para las variables estudiadas. Finalmente, para determinar el grado de dependencia entre las variables se utilizó como criterio la fuerza de relación en una escala cuyo rango oscila entre -1 (negativa perfecta), pasa por cero (no hay relación) y +1 (positiva perfecta), donde no es posible obtener un coeficiente menor de -1 ó mayor de +1 (Hernández, Fernández y Baptista 2003). En este sentido, el resultado obtenido una vez aplicado el coeficiente de correlación de Spearman (rs) fue de 0,99 , lo que indica correlación positiva $\mathrm{y}$ fuerte entre las variables gerencia participativa del director y el rol del docente como promotor social.

\section{Discusión}

Los resultados hallados con respecto a los docentes, o sea, los dirigidos, en cuanto a la dimensión gestión de la variable gerencia participativa, sugieren a la gestión cerrada como la habitual en los centros educativos estudiados. Esto en virtud de que el personal docente encuestado aprecia que el director, aunque en este trabajo los 
mismos opinan lo contrario, da poca importancia a la capacitación del recurso humano, deja de lado el impulso que merece la motivación al logro y genera baja expectativa en la coordinación de esfuerzo (Quinn, 1995; Aguado, 2002).

En este sentido, se presume la práctica de una gerencia que coloca aparte la organización y administración de los recursos para la consecución de los objetivos de la organización; por lo tanto, se despilfarra el recurso humano e invierte mayor esfuerzo en el logro de metas. Al no unificarse de forma consensuada los criterios de trabajo, se está en presencia de gerentes que no toman la iniciativa, ya que están convencidos de que lo hacen bien, pero no fijan metas, ni delegan funciones a sus subalternos. Esto contradice las actividades básicas de la gerencia y hace difícil el logro de cualquier visión (Quinn, 1995; Aguado, 2002).

De igual manera la capacidad, la imaginación, los retos personales y la apertura al cambio que distinguen el liderazgo -también el de la gerencia participativano caracterizan la gestión que se desarrolla en las escuelas urbanas estudiadas. Según lo expresado por los docentes, aunque en total contradicción con lo que piensan los directores, no hay en al menos 15 de los 20 docentes encuestados que escogieron entre el grupo de respuestas positivas o negativas influencia efectiva por parte de los líderes sobre el grupo que permitan generar alternativas de gestión innovadoras en la solución de problemas que confrontan las instituciones educativas. Es decir, los gerentes no son líderes, a pesar de que la capacidad para ejercer un liderazgo efectivo es una de las claves para ser un administrador eficaz (Smith, 1999; Marín, 2004).

La baja capacidad para adaptarse al cambio es lo que caracteriza a muchos docentes de Venezuela; por ejemplo, en el estado Zulia, entidad federal limítrofe con el estado Trujillo, región donde se llevó a cabo la presente investigación, los responsables de la educación formal a nivel de primaria tienen también escasa capacidad para adaptarse y darle respuesta al entorno educativo interno y externo debido a que no promueven el cambio y, por lo tanto, no innovan en el diseño e implementación de los proyectos comunitarios y de plantel (Marcano, 2007).

También, pero en la comunicación y en mayor número de docentes (23/38) e igualmente en contraste a lo dicho por los directores, no se practica la bidireccionalidad como herramienta de utilidad en la ruptura de la estructura interna vertical; las reuniones no son constantes y en las mismas no se escuchan las sugerencias o aportes de todos y cada uno de los actores educativos, aspectos que igualmente definen el accionar educativo en otras investigaciones (Marín, 2004; de Medeiros Calvetti et ál., 2010).

Por otro lado, los docentes, contraviniendo igualmente lo percibido por los directores, manifiestan que existe un déficit en la organización del trabajo institucional en cuanto a la asignación de responsabilidades, organización en equipos y definición de tareas en consonancia con las potencialidades de las personas. De esto se interpreta que se pierde el norte con respecto al trabajo en equipo y no se aprovecha la complementariedad en capacidades de los integrantes del grupo. Por lo tanto, según este y otros trabajos realizados en el estado Trujillo, no se propicia la unión de esfuerzos para facilitar el logro de los objetivos institucionales (Perdomo, 2002; Maduro, 2003; Katzenbach, 2005; Minardi et ál., 2010).

Estos resultados contrastan con los encontrados en un estudio sobre la competencia personal de directores y subdirectores en el municipio Maracaibo del estado Zulia, pues ellos sí poseen, según sus dirigidos, alta capacidad para dirigir la escuela hacia procesos de excelencia y calidad (Marcano, 2007).

Lo hallado en la presente investigación contrasta con el fundamento de la gerencia participativa en cuanto al accionar 
del gerente que en forma consecuente debe desarrollar sus ideas con audacia e innovación y a la vez tener capacidad crítica y constructiva. Es decir, el gerente de la gerencia participativa debe ser una persona asertiva dentro de la organización, innovadora y espontánea, y para ello debe desarrollar habilidades en función de lograr un desempeño gerencial efectivo que sume a favor del éxito cuando logre la ayuda de cada persona relacionada con la organización.

En la consecución de este fin el gerente debe lograr en primer lugar el equilibrio indispensable entre la organización y su entorno, porque individuo y sociedad están indisolublemente unidos. En segundo lugar, debe conducir su gestión hacia la optimización de los recursos que la organización coloca bajo su responsabilidad en los ámbitos tecnológico, administrativo, humano y social, en función de criterios estratégicos adecuados. En tercer lugar, debe encausar bajo una misma dirección los esfuerzos e iniciativas orientadas al crecimiento integral de la organización; en otras palabras, la participación para el consenso y trabajo mancomunado, pero que también implica el involucramiento de todos los actores de la organización, quienes por supuesto deben asumir responsabilidades en esta gestión horizontal (Ferguson, 1980; Quinn, 1995; Galíndez, 2000; Kurosawa, 2001; Villegas, 2003; Siles, 2004; González, 2008).

Por otra parte y por la fuerte correlación positiva entre las variables estudiadas, no parece tampoco prioritaria para los docentes la investigación, otro aspecto fundamental de la promoción social. Esta situación se da a pesar de permitirles ella a los mismos conocer la problemática institucional, comunitaria y del capital social disponible, como nueva praxis pedagógica que persigue sin duda el bien común, fundamentado en el proceso enseñanza-aprendizaje circunscrito al quehacer diario de la comunidad. Esto ya que en la medida en que se haga investigación, habrá sin duda mayor posibilidad de innovar (Rojas, 2002; Arévalo, 2003; Bracho, 2005; Carrillo, 2007; Minardi et ál., 2010).
Asimismo, los directores que participaron en este estudio sí apuestan a la planificación, es decir, al proceso de definir tareas y actividades a desarrollar, fundamentados en la participación abierta y espontánea de cada uno de los actores relacionados con el proceso educativo, luego del diagnóstico de la realidad, en constante consideración de los recursos y tiempo disponible. Sin embargo, esta es otra dimensión faltante en el rol del docente como promotor social, y con ello se arriesga la proyección de los servicios educativos como derecho de los ciudadanos y ciudadanas del país, en un marco de justicia social que promueva la competitividad económica e integración social (Rodríguez, 2000; Rosas, 2005; Dirce Stein Backes et ál., 2009).

Tampoco está arraigada en los actores educativos de las escuelas urbanas estudiadas la dimensión orientador de la variable promotor social con respecto a participación comunitaria por medio de proyectos productivos y lineamientos estratégicos (Martínez 2003). Se interpreta por lo hallado en esta investigación que el docente no aporta o lo hace medianamente experiencias e ideas innovadoras que impulsen los cambios que la escuela y comunidad necesitan (Gillies et ál., 2005; Chacón, 2005; Azuaje, 2007).

Esta situación representa un grave obstáculo para el desarrollo integral de la sociedad porque únicamente con el binomio escuela-comunidad se puede propiciar una educación abierta, máxime que estudios hechos en México (Hernández et ál., 1995) y Chile (Medina 2002) evidencian que en el contexto socio-cultural existen fortalezas y debilidades que pueden restarle coherencia y sentido a la integración escuela-comunidad,que claramente motivan al docente en cuanto el desarrollo y ejecución de proyectos en función de las necesidades reales mediante la organización de grupos conscientes de los objetivos establecidos por el sistema educativo (Mancilla 2004).

En este sentido, el docente en el ejercicio de su profesión no puede mantenerse 
al margen de los acontecimientos del entorno en que él mismo está inmerso, porque su perfil no solamente es técnico profesional, sino también humano, espiritual y social. Es así que estudios hechos en países del continente americano, entre ellos: Estados Unidos, México y Argentina; en europeos, como España y en asiáticos como Filipinas se resalta la importancia del rol de la promoción social en el docente para impulsar y liderar las experiencias de acción comunitaria en la resolución de problemas sociales (Carr y Kemmis, 1988; Alarcón, 1991; Cariño y Dumlao 1992; Proyecto de Investigación Educativa, 1996; Shapiro, 1997; Storck-Hill, 2000; Arévalo, 2003).

De lo anterior se desprende que el docente en la promoción social debe poseer actitudes, habilidades y valores para lograr la integración escuela-comunidad (Bracho, 2005), aspectos no encontrados en este trabajo y en otros realizados en otras regiones del país; por ejemplo, en el estado Portuguesa se reveló que los docentes no planifican ni desempeñan la promoción social (Parada, 1997), en Yaracuy los docentes muestran tendencias moderadas a bajas con respecto a las dimensiones, promoción social y habilidad para dirigir a la comunidad, lo que se traduce en su escasa participación en la atención a los líderes comunitarios y en apatía para la ejecución de sus labores (Zuñiga, 2000).

De allí y contrario al espíritu de la reforma educativa y del proyecto educativo nacional en el ejercicio de la profesión docente, no son estos, al menos para la zona estudiada, los originadores del cambio, pues se requiere pasar del enclaustramiento en las aulas al trabajo con y para las comunidades. Esto al actuar con democracia, autonomía, responsabilidad y compromiso, al tener capacidad para formular políticas públicas y el estar versados en la estructuración y prácticas de valores, reglas y comportamientos para la interacción social, el bien común y el trabajo en equipo.

Se concluye que la gerencia participativa y la promoción social están íntimamente ligadas, que la gestión es cerrada en las instituciones educativas estudiadas, distante del concepto de gerencia participativa, ya que la autoridad se concibe de forma unilateral y la comunicación es solo un mecanismo para transmitir órdenes e instrucciones,sin bidireccionalidad; asimismo, la creatividad, así como la innovación, son elementos poco frecuentes en el desempeño institucional.

Tampoco se da valor a la capacitación del recurso humano, no se escuchan las sugerencias o aportes de los docentes, ni se motiva al logro. Se niega la unidad en los criterios de trabajo, el liderazgo no motiva al cambio y no se cree en el trabajo en equipo; por lo tanto, existen severas falla en la organización del trabajo. De igual manera, se deja de lado el importante rol de promotor social que deben exhibir todos y cada uno de los actores involucrados en la educación formal, ya que no es práctica común investigar la realidad social, el planificar tareas y actividades, y el orientar para la participación comunitaria.

Esta investigación, la primera en el país de esta índole, aporta información valiosa sobre gerencia y promoción social en el ámbito educacional, apoyada en las apreciaciones que sobre las mismas poseen los diversos autores desde el contexto laboral, lo que permitirá, si se toman las correcciones necesarias, adecuar la educación primaria a la realidad del país. Esto con base en directrices participativas y la promoción social, particularmente, porque se demuestra con este y con otros estudios (Perdomo, 2002; Suárez, 2005) que las instituciones educativas trujillanas están cerradas al cambio y al empleo de nuevos enfoques integrales, participativos y prospectivos.

\section{Referencias bibliográficas}

Aguado, S. (2002). La gestión innovadora. Recuperado de http://www.solveidaaguad19.@hotmail.com

Alarcón. (1991). Proyecto Nezahualpilli. 
México: Centro de Estudios Educativos Asociación Civil (CEEAS).

Arévalo, L. (2003). La función docente y la nueva realidad latinoamericana. Recuperado de http://www.luisareval16-23.@hotmail.com

Azuaje, O. (2007). El nuevo rol del docente venezolano. Recuperado de http://www. buenastareas.com/ensayos/Rol-DelDocente-En Venezuela/1396990.html

Bracho, A. (2005). El docente como promotor social. Recuperado de http://www. Gstiopolis.com

Briceño, F. (2001). Aplicación de un modelo de gerencia participativa en la Escuela Técnica Agropecuaria Adolfo Navas Coronado para incrementar la productividad, trabajo de grado, Universidad Nacional Experimental Rafael María Baralt.

Calvetti de Medeiros, A., Castro Pereira, Q., Heckler de Siqueira H., Cecagno D., Lima Moraes C. (2010). "Gestão participativa na educação permanente em saúde: olhar das enfermeiras". Revista Brasileira de Enfermagen, 63(1): 38-42.

Cárdenas, A. (1998). De una educación de masas a una educación de calidad para todos. Ministerio de Educación, Caracas. Recuperado de http://www. bnm.me.gov.ar/cgi-bin/wxis.exe/opac

Cariño, I., y Dumlao, V. (1992). Escuelas y Familias Colaboran en Filipinas para Mejorar los Resultados Escolares. Sistemas de Apoyo Pedagógico Parental (PLSS) Filipinas.

Carr y Kemmis. (1988). Teoría Crítica de la Enseñanza. Barcelona, España. Ediciones Martínez Roca, S.A.

Carrillo, C. (2007). El docente como promotor social. Recuperado de http://www. carlos215ght@hotmail.com

Chacón, P. (2005). El director como promotor social en las Escuelas Bolivarianas del Municipio San Rafael de Carvajal, Estado Trujillo, trabajo de grado, Universidad Valle del Momboy.
Constitución de la República Bolivariana de Venezuela (1999). Caracas: Versión publicada por el Consejo Nacional Electoral, Noviembre de 1999.

Covey, S. (1994). Liderazgo centrado en principios. España: Paidós.

Dirce Stein Backes, Alacoque Lorenzini Erdmann, Andreas Büscher (2009). "Demonstrating nursing care as a social practice". Revista Latino-americana de Enfermagem, 17(6):988-94.

Ferguson, M. (1980). La conspiración de acuario. Barcelona: Kairós.

Galíndez, F. (2000). El Gerente Actual. Recuperado de http://www.ventanaeducativa.com

González TA. 2008). Resultados de la introducción del aprendizaje organizacional en la Empresa Camaguey. Recuperado de http://www.monografías.com

Gillies, R., Jester, D., Hobbs, J. (2005). "Evaluating Perceptions of Community-based Physicians From a High-retention Clerkship”. Family Medicine Journal, 37(9):639-43.

Hernández J, Fernández C, Baptista L. (1995). Propuesta para fortalecer la integración docente-comunidad, dirigido a docentes, padres y representantes de las escuelas básicas en la ciudad de Guadalajara-Jalisco. México.

Hernández S, Fernández C, Baptista L. (2003). Metodología de la investigación, México: McGraw Hill.

Katzenbach, H. (2005). Los grupos de trabajo. Recuperado de http:// www. gestiopolis.com

Kotter, J. (1998). La Gerencia Moderna, Argentina: McGraw Hill.

Kurosawa, I. (2001). Gerencia, IV edición, Caracas: MacGraw Hill.

Maduro, F. (2003). El docente como promotor social en la comunidad, trabajo de grado, Universidad de Oriente.

Mancilla, F (2004). Incorporación de la comunidad en un proceso de micro 
planificación educativa. Trabajo de Grado de la Universidad de Colombia. Marcano, N., de Franco, F. M. (2007). "Competencias personales y gerenciales de los directores y subdirectores de las escuelas básicas". Revista Venezolana de Gerencia, 39:410-430. Marín, E. (2004). La práctica de la gerencia participativa. Recuperado de http://www.eleazarmarin145@ latinmail,com

Márquez, A. (2006). La problemática educativa en Venezuela. Recuperado de http://www.alexismarquez.educa.com

Medina, J. (2002). Ejecución de proyectos en función de necesidades reales en las comunidades integrando a la familia como célula fundamental de la sociedad. Santiago de Chile, Chile.

Medina, R. (2006). La Educación Trujillana: Debilidades y Fortalezas, Trabajo monográfico, Universidad Pedagógica Experimental Libertador, UPEL, Sabana de Mendoza.

Minardi, R., de Melo C. M., Cardoso, M.P. (2010). "Conselho Municipal de Saúde: (re)pensando a lacuna entre o formato institucional e o espaço de participação social”. Ciência \& Saúde Colectiva, 15(5):2437-2445.

Ministerio de Educación (1997). Currículo Básico Nacional. Caracas-Venezuela. Material Mimeografiado.

Ministerio de educación y deportes (2005). Orientaciones para la construcción del proyecto educativo integral comunitario (PEIC). Caracas-Venezuela. Material Mimeografiado.

Ministerio de Educación, Cultura y Deportes (2000). Proyecto educativo nacional. Caracas-Venezuela. Material Mimeografiado.

Odremán, N. (1997). La reforma curricular venezolana. Educación Básica. Revista Ronda de Libros. Año 1. No. 1. Caracas.

Pachano, A. (2006). Manual de Directores de Educación Básica, Caracas: Salvatierra Ediciones, SA.
Parada de M., Y. (1997). Plan de Capacitación Docente del Rol de Promotor Social.

Perdomo, E. (2002). Relación entre la gerencia participativa y el trabajo en equipo desarrollado por los gerentes educativos del Municipio Urdaneta, Estado Trujillo, trabajo de grado. Universidad Nacional Experimental Simón Rodríguez.

Poleo, L. (1995). "La Integración Escuela Comunidad como Estrategia Efectiva para la Resolución de los Problemas Educativos". Revista de Investigación. $3(0)$.

Proyectos de Investigación Educativa (PROMIE). (1996). Documento del Ministerio de Educación de Argentina. Buenos Aires: Autor.

Quinn, R. (1995). Maestría en Gestión de las Organizaciones. Traducción Carmen León Pérez. Madrid-España: Ediciones Díaz Santos.

Requeijo, D., y Lugo, A. (1995) Administración escolar. Caracas: Biosfera.

Robins, S. (1998). Fundamentos de administración. México. Editorial Prentice Hall.

Rodríguez, P. (2000). Planificación docente. Recuperado de http://www.ucn. es/BUCM

Rojas, M. (2002). El docente como promotor de la integración escuela comunidad en la Unidad Educativa Humberto Guerrero de Cabimas, Estado Zulia, trabajo de grado, Universidad del Zulia.

Romero, C. (1996, Octubre). El gerente global. Gerente, 50.

Rosas, A. (2005). Planificación institucional por procesos. México: Progreso.

Shapiro. (1997). La Educación en los Estados Unidos. Paradigmas Educativos de Hoy. [Ponencia]. Fondo Editorial IPASME, Edición Especial. Caracas.

Siles, A. (2004). La gerencia participativa. Recuperado de http:// www.monografías.com 
Smith, W. (1999). La gerencia, Textos técnicos, Colombia: Ediciones Progreso.

Storck, J., y Hill, P. (2000). "Knowledge Diffusion trough Strategic Comunities". Sloan Management Review. EEUU.

Suárez, A. (2005). La práctica de la gerencia participativa en las Escuelas Bolivarianas del Municipio
Candelaria, trabajo de grado, Universidad Valle del Momboy.

Villegas, J. (2003). La Gerencia. Recuperado de http://www.rincondelvago.com

Zuñiga, A. (2000). Modelo de asesoramiento para capacitar a los docentes hacia un liderazgo comunitario. Yaracuy. Venezuela. 
